\title{
Choosing appropriate language to reduce the stigma around mental illness and substance use disorders
}

\author{
Nora D. Volkow (iD ${ }^{1 凶}$, Joshua A. Gordon ${ }^{2}$ and George F. Koob ${ }^{3}$ \\ (C) This is a U.S. government work and not under copyright protection in the U.S.; foreign copyright protection may apply 2021
}

Neuropsychopharmacology (2021) 46:2230-2232; https://doi.org/10.1038/s41386-021-01069-4

The words we use to describe mental illnesses and substance use disorders (addiction to alcohol and other legal and illegal drugs) can impact the likelihood that people will seek help and the quality of the help they receive. Research indicates that stigma-negative attitudes toward people based on distinguishing characteristicscontributes in multiple ways to poorer health outcomes; consequently, it has been identified as a critical focus for research and interventions [1].

Researchers and clinicians can help reduce stigma by carefully choosing the words they use to describe mental health conditions and addictions and the people who are affected by them. Language plays a major role in shaping people's thoughts and beliefs, and scientific communication can sometimes be an inadvertent vector of harmful stereotypes and assumptions. Utilizing scientifically accurate language and terms that centralize the experience of patients who experience psychiatric conditions and that validate their worth can positively affect how they are treated within healthcare and in society more generally.

Mental illnesses and substance use disorders have always been among the most stigmatized of health conditions. Despite advances over the last few decades in educating healthcare providers and the public about the genetic and neurobiological underpinnings of these conditions, stigma persists. Efforts to reduce stigma are considered to be an important component of removing barriers to care, especially given the fact that $35 \%$ of people with serious mental illness in the U.S., and nearly $90 \%$ of people with substance use disorders, do not receive treatment [2]. Stigma is one of several factors that can limit the utilization of treatment services [3]. For instance, people with alcohol use disorder (AUD) who perceive a high degree of public stigma toward those with their condition were about half as likely to seek help as those perceiving a low degree of stigma [4].

Even care providers sometimes stigmatize individuals with mental illnesses. Bias among medical professionals and mental health service providers can reduce the likelihood that individuals with mental illnesses will be offered or receive appropriate treatment or be referred for specialty care [5]. Efforts to reduce provider stigma hold promise. In one recent study, testimony from patients who benefited from treatment for mental illness reduced stigma among medical students. Such approaches could help improve the likelihood and quality of mental healthcare delivery [6].

Additional damaging effects of stigma arise when it is internalized-known as self-stigma. Self-stigma significantly decreases interest in seeking help for mental health concerns $[7,8]$. Research shows that self-stigma negatively impacts the recovery of people with severe mental illnesses by decreasing their self-esteem and self-worth, reducing their hope for recovery, affecting their social relationships, and worsening their psychiatric symptoms. Studies also suggest that self-stigma increases avoidant coping and suicide risk as well reducing treatment adherence and vocational functioning [9].

Stigma against people with substance use disorders has proven particularly intractable. The public continues to see these disorders as character flaws or even as deviance, contributing to a treatment-averse mindset even among some physicians and healthcare providers. Addiction is a brain disorder and, as such, should be considered as treatable like any other medical condition.

Pioneering research showing the power of word choice in determining professionals' motivation to treat or not treat people with addictive disorders was conducted over a decade ago by researchers at Harvard [10]. In one study using case vignettes, doctoral-level clinicians in mental health and addiction were more likely to favor punishment (a jail sentence) versus treatment for a character when that individual was described as a "substance abuser," versus when they were described as having a "substance use disorder"-all other words in the descriptions being identical. This finding has been replicated with mental health professionals and other groups.

Given the persistence of implicitly stigmatizing terms like "addict," "alcoholic," "abuser," and so on, even in professional literature, it is perhaps not surprising that the treatment gap is even wider for substance use disorders than for other psychiatric conditions. Despite being in the midst of a devastating, widely publicized opioid crisis, and despite the existence of three effective medications to treat opioid use disorder (OUD), in 2019 only $18 \%$ of people with OUD received medications to treat it [2]. Treatment rates for AUD are especially low (e.g., 7.6\% in 2019) [2]. There are three effective medications to treat AUD, yet in 2019 fewer than $2 \%$ of people with AUD received any of those medications $[2,11]$.

In 2019 , over $17 \%$ of people with an alcohol or other substance use disorder reported they did not seek treatment due to concerns that their neighbors or community would have a negative opinion of them [2]. In addition, previous painful experiences of discrimination in healthcare settings may cause

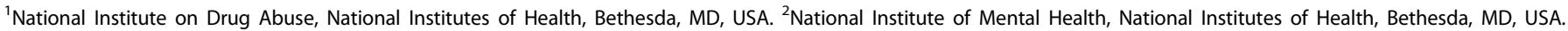
${ }^{3}$ National Institute on Alcohol and Alcoholism, National Institutes of Health, Bethesda, MD, USA. ${ }^{凶}$ email: nvolkow@nida.nih.gov 
people with addiction to avoid seeking treatment. Like stigma for other mental illnesses, stigma around addiction is internalized as an ongoing source of shame, and the resulting distressing isolation can lead to further substance misuse [12].

Stigma around treatments for addiction is also an issue. For instance, the persistent belief that agonist medications for OUD (methadone and buprenorphine) "just substitute one addiction for another" has helped perpetuate their low implementation in healthcare and justice settings. The widely used term "medicationassisted treatment" (MAT) also stigmatizes these pharmacotherapies as less than adequate in their own right and as distinct from medications for other medical conditions, which are simply referred to as medications to treat cancer, HIV, hypertension, and so on. "Medication to treat substance use disorder" —or more specifically, "medication to treat opioid use disorders" or "medication to treat AUD" - should be used instead of MAT. Note that, as with other mental disorders, there is mutual benefit of both pharmacotherapies and behavioral treatments for substance use disorders.

\section{PERSON-CENTERED LANGUAGE}

Language norms are continuously shifting, and not all patient groups necessarily agree on preferred terms. But generally speaking, researchers, clinicians, and others who interact with or communicate about mental and substance use disorders are encouraged to replace potentially stigmatizing terms and labels with neutral, person-centered language. Person-centered language reflects that the disorder or illness is only one aspect of a person's life, not the defining characteristic.

Using a person-centered approach, for example, someone should be described as "a person with schizophrenia" or "a person with psychosis," rather than being described as "schizophrenic" or "psychotic." Similarly, instead of describing a person with drug addiction as an "addict" or "abuser," refer to them as having a substance use disorder or having an addiction-both are acceptable, even if the former is more precise. Likewise, refer to someone as being "a person with an AUD" rather than "an alcoholic." Moreover, the word "alcoholic" should not be used as an adjective; for instance, the term "alcohol-associated liver disease" should be used instead of "alcoholic liver disease," to lessen the potential impact of stigma on care for people with liver disease, including those in need of a liver transplant [13].

Care should also be taken to avoid terminology that implies a negative value judgment. For example, when referring to suicide, care should be taken to say "died by suicide" rather than "committed suicide," since "commit" connotes criminality or sin. Suicide attempts should also not be described as "successful" or "unsuccessful" (or "failed"). Instead, use "survived a suicide attempt," just as one might describe an individual who has survived cancer or a heart attack.

Similarly, in the context of substance use, the words "clean" and "dirty" should be avoided when referring to drug toxicology results (i.e., negative or positive urine tests); nor should "clean" be used to refer to being abstinent from drugs or in recovery from a drug use disorder. And importantly, the word "abuse," both as noun and verb, should be replaced by "misuse" or just "use." Although "abuse" was once a diagnostic category and still appears as such in some surveys, its removal from the DSM-5 in 2013 reflected a major progressive shift toward conceptualizing people with addiction as having a treatable medical condition rather than as being guilty of misbehavior. The term "abuse" remains in the names of our NIH Institutes that study addiction, although there is increased interest-both in the scientific community as well as among the affected patient populations-in seeing those names changed to reflect current understandings of addiction as a disorder.
Comprehensive guidelines for communicating about mental illness and substance use disorders in a nonstigmatizing way are available in the literature [14] and on the websites of NIDA and NIAAA. But since principles of nonstigmatizing language are not always consistent between groups and since language norms shift, it is important for researchers and institutions to engage directly with communities affected by the conditions they study, to understand what those communities prefer.

Stigma is particularly difficult to eliminate, even with educational and other interventions, and carefully considered language is only one part of addressing it. But it is also one of the most immediate ways in which researchers and others who communicate about stigmatized conditions can effect change. Appropriate terminology can encourage a person-centered framing of the condition, one that implicitly reinforces that affected individuals deserve compassion and care and that signals what science has shown to be the case: that in many or most cases, mental illnesses and substance use disorders can be treated or managed, and that people can hope to achieve recovery.

This kind of shift in mindset is crucial for mobilizing needed resources toward the provision of quality mental health and addiction services and eroding the prejudices that keep people who need those services from seeking or receiving them. It is also crucial to help educate the wider public about conditions that have long been, and continue to be, greatly misunderstood.

\section{REFERENCES}

1. National Academies of Sciences, Engineering, and Medicine. Ending Discrimination Against People with Mental and Substance Use Disorders: the Evidence for Stigma Change. Washington, DC: The National Academies Press; 2016. https://doi. org/10.17226/23442.

2. Han B. Key substance use and mental health indicators in the United States: results from the 2019 National Survey on Drug Use and Health (HHS Publication No. PEP20-07-01-001, NSDUH Series H-55). Rockville, MD: Center for Behavioral Health Statistics and Quality, Substance Abuse and Mental Health Services Administration; 2020 .

3. Hammarlund R, Crapanzano KA, Luce L, Mulligan L, Ward KM. Review of the effects of self-stigma and perceived social stigma on the treatment-seeking decisions of individuals with drug- and alcohol-use disorders. Subst Abus Rehabil. 2018;9:115-36. https://doi.org/10.2147/SAR.S183256. Published 2018 Nov 23.

4. Keyes KM, Hatzenbuehler ML, McLaughlin KA, Link B, Olfson M, Grant BF, et al. Stigma and treatment for alcohol disorders in the United States. Am J Epidemiol. 2010;172:1364-72. https://doi.org/10.1093/aje/kwq304.

5. Thornicroft G, Rose D, Mehta N. Discrimination against people with mental illness: what can psychiatrists do? Adv Psychiatr Treat. 2010;16:53-9. https://doi.org/ 10.1192/apt.bp.107.004481.

6. Tergesen CL, Gurung D, Dhungana S, Risal A, Basel P, Tamrakar D, et al. Impact of Service User Video Presentations on Explicit and Implicit Stigma toward Mental Illness among Medical Students in Nepal: a Randomized Controlled Trial. Int J Environ Res Public Health. 2021;18:2143. https://doi.org/10.3390/ijerph18042143. PMID: 33671743; PMCID: PMC7926497.

7. Lannin DG, Vogel DL, Brenner RE, Abraham WT, Heath PJ. Does self-stigma reduce the probability of seeking mental health information? J Couns Psychol. 2016;63:351-8. https://doi.org/10.1037/cou0000108.

8. Jennings KS, Cheung JH, Britt TW, Goguen KN, Jeffirs SM, Peasley AL, Lee AC. How are perceived stigma, self-stigma, and self-reliance related to treatment-seeking? A three-path model. Psychiatr Rehabil J. 2015;38(Jun):109-16. https://doi.org/ 10.1037/prj0000138. Epub 2015 Apr 6. PMID: 25844914.

9. Yanos PT, DeLuca JS, Roe D, Lysaker PH. The impact of illness identity on recovery from severe mental illness: a review of the evidence. Psychiatr Res. 2020;288 112950. https://doi.org/10.1016/j.psychres.2020.112950. ISSN 0165-1781.

10. Kelly JF, Westerhoff CM. Does it matter how we refer to individuals with substance-related conditions? A randomized study of two commonly used terms. Int J Drug Policy. 2010;21:202-7. https://doi.org/10.1016/j.drugpo.2009.10.010. Epub 2009 Dec 14. PMID: 20005692.

11. Han B, Jones CM, Einstein EB, Powell P, Compton WM. Use of medications for alcohol use disorder among adults in the United States. JAMA Psychiatry. 2021. https://doi.org/10.1001/jamapsychiatry.2021.1271. Online ahead of print. 
12. Volkow ND. Stigma and the Toll of Addiction. N Engl J Med. 2020;382:1289-90. https://doi.org/10.1056/NEJMp1917360. PMID: 32242351.

13. Pimienta M, Dodge J, Terrault NA. The Internet as a Tool for Liver Transplant Programs to Combat Stigma Related to Alcohol Use Disorder. Hepatol Commun. 2021;5(Feb):155-7. https://doi.org/10.1002/hep4.1649. PMID: 33553965; PMCID: PMC7850306.

14. McGinty E, Pescosolido B, Kennedy-Hendricks A, Barry CL. Communication Strategies to Counter Stigma and Improve Mental Illness and Substance Use Disorder Policy. Psychiatr Serv. 2018;69(Feb):136-46. https://doi.org/10.1176/ appi.ps.201700076. PMID: 28967320; PMCID: PMC5794622.

\section{ACKNOWLEDGEMENTS}

The authors thank Emily B. Einstein, Beth Han, and Eric M. Wargo (NIDA); Lisa Alberts, Claire Cole, Lisa Colpe, Andrew Hooper, Julie Mason, and Natalie Zeigler (NIMH); and Trish Powell, Aaron White, and Bridget Williams-Simmons (NIAAA) for their help preparing this paper.

\section{AUTHOR CONTRIBUTIONS}

NDV, JAG, and GFK contributed equally to the conception, drafting, and revision of the paper.

\section{COMPETING INTERESTS}

The authors declare no competing interests.

\section{ADDITIONAL INFORMATION}

Correspondence and requests for materials should be addressed to N.D.V.

Reprints and permission information is available at http://www.nature.com/ reprints

Publisher's note Springer Nature remains neutral with regard to jurisdictional claims in published maps and institutional affiliations. 